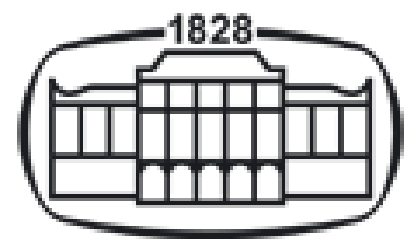

\title{
AKADÉMIAI KIADÓ
}

Quantitative and qualitative dynamics of exotic and native blowflies (Diptera: Calliphoridae) with migrations among municipalities

Author(s): T.C. Moretti, R.M. Coutinho, R.A. Moral, C.P. Ferreira and W.A.C. Godoy

Source: Community Ecology, 2013, Vol. 14, No. 2 (2013), pp. 249-257

Published by: Akadémiai Kiadó

Stable URL: https://www.jstor.org/stable/24113586

JSTOR is a not-for-profit service that helps scholars, researchers, and students discover, use, and build upon a wide range of content in a trusted digital archive. We use information technology and tools to increase productivity and facilitate new forms of scholarship. For more information about JSTOR, please contact support@jstor.org.

Your use of the JSTOR archive indicates your acceptance of the Terms \& Conditions of Use, available at https://about.jstor.org/terms 


\title{
Quantitative and qualitative dynamics of exotic and native blowflies (Diptera: Calliphoridae) with migrations among municipalities
}

\author{
T.C. Moretti ${ }^{1}$, R.M. Coutinho ${ }^{2}$, R.A. Moral $^{3}$, C.P. Ferreira ${ }^{4}$ and W.A.C. Godoy ${ }^{5}$ \\ ${ }^{1}$ Departamento de Biologia, Faculdade de Filosofia, Ciências e Letras de Ribeirão Preto, Universidade \\ de São Paulo (USP). Av. Bandeirantes, 3900, Monte Alegre, 14040-901, Ribeirão Preto, SP, Brazil. \\ Corresponding author.E-mail: tcmoretti@yahoo.com.br \\ ${ }^{2}$ Instituto de Física Teórica, Universidade Estadual Paulista Júlio de Mesquita Filho (UNESP). \\ R. Dr. Bento Teobaldo Ferraz, 271 - Bloco II, Barra Funda, 01140-070, São Paulo, SP, Brazil \\ ${ }^{3}$ Departamento de Ciências Exatas, Escola Superior de Agricultura Luiz de Queiroz, Universidade \\ de São Paulo (USP). Av. Pádua Dias, 11, 13418-900, Piracicaba, SP, Brazil \\ ${ }^{4}$ Departamento de Bioestatística, Instituto de Biociências, Universidade Estadual Paulista Júlio de \\ Mesquita Filho (UNESP). Distrito de Rubião Junior, s/n, 18618-970, Botucatu, SP, Brazil \\ ${ }^{5}$ Departamento de Entomologia e Acarologia, Escola Superior de Agricultura Luiz de Queiroz, Universidade \\ de São Paulo (USP). Av. Pádua Dias, 11, 13418-900, Piracicaba, SP, Brazil
}

Keywords: Chrysomya albiceps, Chrysomya megacephala, Forensic entomology, Lucilia eximia, Mathematical model, Population dynamics, Spatial structure.

\begin{abstract}
The population dynamics of blowflies (Diptera: Calliphoridae) has been investigated in studies combining different mathematical formalisms, with estimates of demographic parameters and spatial models. However, these applications are limited to laboratory data only. In this study, we investigated the population dynamics of three species of blowflies [Chrysomya albiceps (Wiedemann), Chrysomya megacephala (F.) and Lucilia eximia (Wiedemann)] in a mathematical model that includes parameters estimated in the laboratory and population sizes estimated from field collections, in order to simulate the dynamics of local migration. The model combines experimental estimates of fecundity and survival with abundance data obtained in field collections, to analyze comparatively the population dynamics of the three blowfly species, taking into account the theoretical movement by individuals among municipalities with different urbanization profiles. The ecological patterns of oscillation observed depended on the municipality only for $C$. albiceps, a species with special demographic characteristics that are probably associated with predatory and cannibalistic behaviors. The bifurcation diagrams showed that intermediate migration rates stabilize populations. Although the proposed model considers only six municipalities in a closed system, the study was able to show different impacts of local migration on the quantitative and qualitative population behaviors, by using different connectivity levels arising from the different distances among areas.
\end{abstract}

\section{Introduction}

Ecological modeling has been used to show population oscillations or persistence patterns of insects in both the laboratory and the field (Desharnais 2005). Population models extract information from laboratory experiments in order to investigate specific ecological aspects that are important for conservation and pest control (Yurk and Powell 2010). Field studies are important to supply models with data describing more realistic situations, in order to confirm patterns obtained in the laboratory or to compare results by using analytical tools (Petrovskii et al. 2012). Dynamic behavior of insects has been assessed by using models that explore the association between stability and magnitude of demographic parameter values, resulting in complex patterns in response to population growth (Desharnais 2005). Particularly, population dynamics has been strongly linked to laboratory ecology by the use of models, which have been particularly useful for understanding development, persistence, life history, foraging, demography, nonlinear dynamics, evolutionary dy- namics and parasitism (Burd and Howard 2005, Desharnais 2005, Yurk and Powell 2010). Modeling focused on field studies has more recently been emphasizing swarm systems, foraging environment, epidemics and insect outbreaks (Fuller et al. 2012, Granovskiy et al. 2012, Hamann and Schmick1 2012).

Mathematical modeling of insect population dynamics provides interesting insights into comparative dynamics, because demographic parameters of exotic species generally exhibit larger differences in magnitude than those of native species (Godoy et al. 2001). These differences may drive dynamic behaviors, resulting in different spatio-temporal patterns. Generally, simple dynamics, characterized by monotonic equilibrium, is established when the magnitude of growth rates is low, compared to complex dynamics, which are characterized by periodic cycles or chaos (Desharnais 2005). Historically, blowflies (Diptera: Calliphoridae) have been cited as important examples of insects that exhibit complex cycles in the laboratory (Gurney et al. 1980). This type of behavior has also been observed in flour beetles, for which 
the population dynamics have been intensively studied for successive years (Costantino et al. 2005).

The above-mentioned examples describe theoretical ecological patterns very well, taking into account the trajectory of time series. Time series make it possible to determine the tendencies and/or sensitivity of population parameters, but always consider only one dimension, time. In recent years, ecologists have been concerned about the kind of population behavior that could be expected if another dimension, space, is taken into account. Space can be interpreted as the movement of insects among patches (Okubo and Levin 2001). Perhaps the movement among patches is strongly dependent on connectivity. Connectivity, which is the degree to which populations are able to or prevented from moving among patches (Rösch et al. 2013), has been viewed as a major factor capable of determining species distributions (Moilanen and Hanski 2001). Extinction-colonization dynamics is probably strongly associated with connectivity (Moilanen and Nieminen 2002).

In insects, the spatial structure has been identified as a stabilizing factor in single-species population dynamics. However, little is known about possible synergic effects of the combination of demography and local migration, since demographic factors may be responsible for spatio-temporal variations (Reigada et al. 2013).

Blowflies, apart from being extensively studied because they are important vectors of pathogens and causative agents of myiasis, and are useful in maggot debridement therapy and for estimating the minimum postmortem interval (Godoy 2007, Moretti and Godoy 2013), provide a valuable opportunity to assess demographic changes in response to competition for food in time and space. Nicholson $(1954,1957)$ experimentally studied population tendencies over time, revealing unpredictable ecological patterns of blowfly oscillations. Biological invasions by blowflies from the Old World to the New World have been documented over the last four decades, possibly in response to greater connectivity among continents (Coutinho et al. 2012).

However, particularly in Brazil, the scenario of this invasion has been changing in a singular way. The prevalence of species has changed over the last decades, inverting their abundance status. This is especially clear for the exotic species Chrysomya megacephala (F.) and the native species $L u$ cilia eximia (Wiedemann), which have been changing their prevalence, apparently changing habits and exhibiting new preferences for areas. Certainly, the dynamics in time and dynamics in space are interdependent to some extent. The stabilizing effect of space on the population dynamics of blowflies has been investigated in studies that combine different mathematical formalisms by employing population growth and lattice models (Godoy et al. 1997, 2001, Serra et al. 2007). However, these applications are limited to laboratory data. Different areas may influence the demography of insects, mainly in highly heterogeneous environments. For insects, which are able to change habitats and migrate among urban, farm and forest environments, the urban habitat may exert a significant influence on the population dynamics $(\mathrm{Ru}-$ bio et al. 2012). Habitat quality and the impact of natural enemies might profoundly affect metapopulation dynamics and the viability of local populations (Choutt et al. 2011).

The objective of this study was to propose a mathematical model that combines the use of demographic parameters estimated in the laboratory and abundance data obtained in field collections to analyze comparatively the population dynamics of three species of blowflies [Chrysomya albiceps (Wiedemann), Chrysomya megacephala (F.) and Lucilia eximia (Wiedemann)], taking into account the theoretical movement by individuals among municipalities with different urbanization profiles. The stabilizing influence of local migration was investigated algebraically, and the different results were discussed in light of the dynamic equilibrium theory, in order to compare the different ecological patterns of population behavior on the basis of the field and laboratory parameters.

\section{Materials and methods}

Some parts of the methods described here are similar to those used by Moretti et al. (2011) and Moretti and Godoy (2013), but are repeated here for the sake of clarity and convenience.

\section{Study sites}

The collections were carried out in rural, urban, and forest environments in six municipalities in São Paulo State,

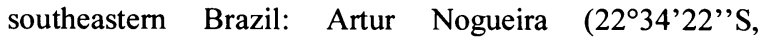

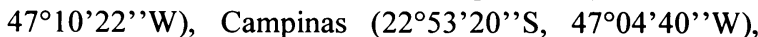
Cosmópolis $\quad\left(22^{\circ} 38^{\prime} 45^{\prime \prime} \mathrm{S}, \quad 47^{\circ} 11^{\prime} 46^{\prime \prime} \mathrm{W}\right)$, Jundiaí

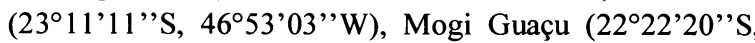
$\left.46^{\circ} 56^{\prime} 32^{\prime \prime} \mathrm{W}\right)$ and Paulínia $\left(22^{\circ} 45^{\prime} 40^{\prime \prime} \mathrm{S}, 47^{\circ} 09^{\prime} 15^{\prime \prime} \mathrm{W}\right)$ Figure 1 shows the location of the municipalities and the distances between them. We chose these six municipalities because they are representative of the different public-sanitation conditions existing in the state of São Paulo.

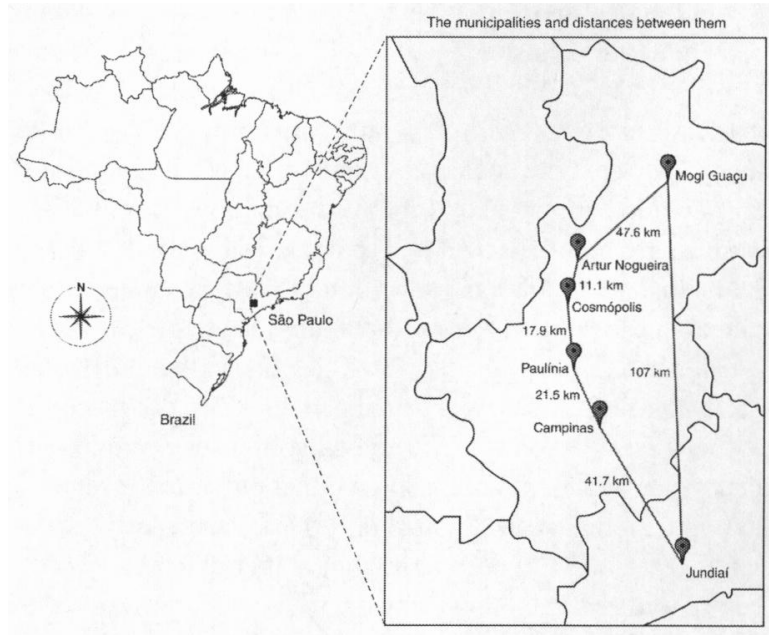

Figure 1. Location of the municipalities and the distances between them (adapted from Moretti et al. 2011). 
Table 1. Mean survival and fecundity rates for each species (Lucilia eximia, Chrysomya albiceps and Chrysomya megacephala) and larval densities (adapted from Godoy et al. 1997, Godoy et al. 2001, Serra et al. 2007).

\begin{tabular}{ccccc}
\hline \multicolumn{5}{c}{ L. eximia } \\
\hline Density & Replicates & Mean survival & $\mathbf{n}$ & Mean fecundity \\
\hline 100 & 2 & 0.9150 & 32 & 6.53 \\
200 & 2 & 0.8400 & 32 & 7.03 \\
400 & 2 & 0.5900 & 32 & 6.14 \\
600 & 2 & 0.3800 & 31 & 5.29 \\
800 & 2 & 0.3600 & 32 & 4.05 \\
\hline \multicolumn{5}{c}{ C. albiceps } \\
\hline Density & Replicates & Mean survival & $\mathbf{n}$ & Mean fecundity \\
\hline 100 & 2 & 0.5400 & 25 & 26.46 \\
200 & 2 & 0.3400 & 54 & 21.02 \\
400 & 2 & 0.1200 & 29 & 19.24 \\
600 & 2 & 0.0720 & 17 & 15.91 \\
800 & 2 & 0.0690 & 22 & 13.63 \\
1,000 & 2 & 0.0200 & 10 & 10.00 \\
\hline \multicolumn{5}{c}{ C. megacephala } \\
\hline Density & Replicates & Mean survival & $\mathrm{n}$ & Mean fecundity \\
\hline 200 & 2 & 0.6650 & 47 & 21.79 \\
400 & 2 & 0.5510 & 52 & 20.40 \\
600 & 2 & 0.3000 & 31 & 17.76 \\
800 & 2 & 0.3494 & 58 & 13.84 \\
1,000 & 2 & 0.2700 & 43 & 13.28 \\
1,200 & 2 & 0.2324 & 53 & 10.00 \\
1,400 & 1 & 0.0428 & 11 & 7.16 \\
1,600 & 1 & 0.0406 & 11 & 7.65 \\
1,800 & 1 & 0.0455 & 19 & 9.07 \\
2,000 & 1 & 0.1030 & 18 & 9.65 \\
\hline \multicolumn{5}{c}{}
\end{tabular}

The rural areas in these municipalities are homogeneous, with moderate agricultural activity and livestock farming, and a few scattered houses. Most of the urban sites have modest commercial activity, except Campinas $(1,080,113$ inhabitants and an area of $795 \mathrm{~km}^{2}$ ) and Jundiai (370,126 inhabitants and an area of $431 \mathrm{~km}^{2}$ ) (IBGE 2012), the two largest cities monitored, which have very high levels of urbanization, dense housing and intense commerce. Finally, the forest sites are mainly remnant woodland patches with similar phytophysiognomic features, except Campinas, where the forest area is a 250-ha mesophilic semideciduous Atlantic Forest fragment (Morellato and Leitão Filho 1995) surrounded by human dwellings (Moretti et al. 2011).

All these cities have the same type of weather according to the Köppen climate classification: Cwa, a subtropical climate, with cool dry winters (temperatures below $18^{\circ} \mathrm{C}$ ) and warm humid summers (with the mean temperature in the warmest month above $22^{\circ} \mathrm{C}$ ), as generally occurs in the State of São Paulo, mainly in the central and eastern regions, at altitudes between 500 and $700 \mathrm{~m}$ (Setzer 1966).

\section{Field and laboratory procedures to obtain abundance data}

Monthly collections were made from September 2006 through October 2007. Each of the environments in each municipality was monitored using six traps per month, two for each kind of bait, totalling 18 traps per municipality/month and 1,512 sample units during the entire study (18 traps $\times 6$ cities $\times 14$ months of collection). Baits composed of $12 \mathrm{~g}$ of one of the following: fish (sardines), beef liver, or chicken gizzards were employed, after being allowed to putrefy for approximately $48 \mathrm{~h}$ at room temperature. The carrion traps were installed approximately $15 \mathrm{~m}$ apart at the collection sites. Each trap was made of two 2.0-liter plastic soft-drink bottles, each approximately $30 \mathrm{~cm}$ in height and $10 \mathrm{~cm}$ in diameter. The bottoms of both bottles were removed to allow one to fit into the other and to allow insects to enter through the bottom opening of the lower bottle, which was painted black. The cap of the lower bottle was also removed, so its top end was open. Each bait was placed at the top end of the lower bottle with a small metal hook, and was replaced in the traps every $24 \mathrm{~h}$.

Each trap was suspended by a cord from a tree branch, approximately $180 \mathrm{~cm}$ above the ground. The traps remained exposed at the study site for a period of $72 \mathrm{~h}$, after which all insects trapped in the upper bottle were collected, taken to the laboratory, and killed by freezing at $-20^{\circ} \mathrm{C}$, until later identification. The carrion-baited trap was illustrated by Moretti et al. (2011) and Moretti and Godoy (2013). Part of the collected material was mounted and deposited in the ESALQ Entomological Museum, Department of Entomology and Acarology, ESALQ/USP, Piracicaba, São Paulo, Brazil. The remaining specimens were preserved in $70 \%$ ethanol.

\section{Demographic parameter values obtained in laboratory}

Fecundity and survival were estimated in the laboratory by employing experiments to simulate the variation of these parameters as a function of intraspecific competition for food. Increasing larval densities were set up to estimate the influence of competition for food on fecundity and survival. A detailed description of these procedures was provided by Godoy et al. (1997, 2001). The mean survival and fecundity 
Table 2. Total abundance of Chrysomya albiceps, Chrysomya megacephala and Lucilia eximia per municipality during the collection period.

\begin{tabular}{lcccccc}
\hline & \multicolumn{5}{c}{ Municipalities } \\
\cline { 2 - 7 } Species & Artur Nogueira & Campinas & \multicolumn{1}{c}{ Cosmopolis } & Jundial & Mogi-Guaçu & Paulinia \\
\hline C. albiceps & 1,290 & 1,781 & 1,022 & 368 & 531 & 488 \\
C. megacephala & 518 & 687 & 872 & 324 & 411 & 404 \\
L. eximia & 781 & 486 & 437 & 521 & 340 & 325
\end{tabular}

rates for L. eximia, C. albiceps and C. megacephala at different larval densities obtained in these studies are provided in Table 1.

\section{Mathematical modeling}

In order to model fly dynamics, Prout and McChesney (1985) developed a discrete-time mathematical model, which was subsequently used in blowfly ecology by Von Zuben et al. (1993) and Godoy et al. (2001). This model includes density dependence, and assumes that the population size at generation $t+1$ depends on the reproductive capability of the surviving females at generation $t$. Therefore, the main parameters of the model are fecundity (egg production) and survival, expressed as functions of the density. The sex ratio is considered to be $1: 1$, so the females account for half of the population. The model is written as:

$N_{t+1}=G\left(N_{t}\right)=\frac{1}{2} F\left(N_{t}\right) S\left(N_{t}\right) N_{t}$,

where $N_{t}$ is the number of individuals at generation $t$, and $F\left(N_{t}\right)$ and $S\left(N_{t}\right)$ are the functions that describe the fecundity and survival rates, respectively. These functions, which depend on the larval density, are described as an exponential decline (Silva et al. 2003), written as:

$$
\begin{aligned}
& F\left(N_{t}\right)=P \exp \left\{-p N_{t}\right\}, \\
& S\left(N_{t}\right)=Q \exp \left\{-q N_{t}\right\},
\end{aligned}
$$

where $P$ and $Q$ describe the maximum fecundity and survival rates, respectively, and $p$ and $q$ are coefficients related to the rate of decline of the exponential curves.

In this study, we consider several sites whose local dynamics will be described by model (1), supplemented by migration functions in order to reproduce the dynamics that might occur in a closed system, composed by six municipalities located in Săo Paulo State, Brazil. The new model is:

$N_{t+1}^{(i)}=\left(1-\sum_{j \neq i} m_{i j}\right) G_{i}\left(N_{t}^{(i)}\right)+\sum_{j \neq i} m_{j i} G_{j}\left(N_{t}^{(j)}\right) ;$

$i=1,2, \ldots, 6 ; j=1,2, \ldots, 6$,

$m_{i j}=M_{i} \frac{\exp \left(-\frac{d_{i j}}{\alpha}\right)}{\sum_{j \neq i} \exp \left(-\frac{d_{i j}}{\alpha}\right)}, 0 \leq M_{i} \leq 1$,

where the superscript $i$ denotes the site, $G_{i}$ is the growth func- tion with site-dependent parameters, $m_{i j}$ is the migration rate from municipality $i$ to municipality $j, m_{j i}$ is the migration rate from municipality $j$ to municipality $i, \alpha$ is the range of flight, $M_{i}$ (the values of which are assumed to be independent of site $i$ ) is the likelihood of migrating away from site $i$, and $d_{i j}$ is the shortest distance between municipality $i$ and municipality $j$. When $\alpha$ decreases, the migration rates shift toward closer sites, as

$$
\begin{aligned}
& \lim _{\alpha \rightarrow 0^{+}} m_{i j}=M_{i} \text { if } d_{i j}<d_{i k} \text { for all } k \neq j, \\
& \lim _{\alpha \rightarrow 0^{+}} m_{i j}=0 \text { otherwise. }
\end{aligned}
$$

Conversely, when $\alpha$ increases substantially, the migration rates are determined only by the likelihood of migrating, as $\lim _{\alpha \rightarrow \infty} m_{i j}=\frac{M_{i}}{6}$.

The coefficients of $F\left(N_{t}\right)$ and $S\left(N_{t}\right)$ were estimated by Godoy et al. (2001), who used data from laboratory experiments. Studying the equilibrium of the Prout model by setting $N_{t+1}$ $=N_{t}=u^{*}$, it follows that:

$$
\begin{aligned}
& u^{*}=\frac{1}{2} F\left(u^{*}\right) S\left(u^{*}\right) u^{*}, \\
& u^{*}=\frac{1}{2} P Q \exp \left\{-(p+q) u^{*}\right\} u^{*}
\end{aligned}
$$

By isolating $(p+q)$, the following is obtained:

$(p+q)=\ln \left(\frac{P Q}{2}\right) \frac{1}{u^{*}}$.

In this study, only the values for $P$ and $Q$, the maximum fecundity and survival rates, were obtained from the experiments by Godoy et al. (2001). By setting $u^{*}$ equal to the sampling average for each municipality, different $(p+q)$ values are obtained for each species and each municipality. By taking that estimate from the Prout model without immigration, we are effectively assuming that total migration, that is, immigration minus emigration, is zero in each municipality. While this is not true in general nor is it expected from observational data, it is nonetheless a good approximation for the average population over many generations.

\section{Results and discussion}

Table 2 shows the abundance of $C$. albiceps, $C$. megacephala and $L$. eximia per municipality of collection. The results suggest that $C$. albiceps had its largest population 


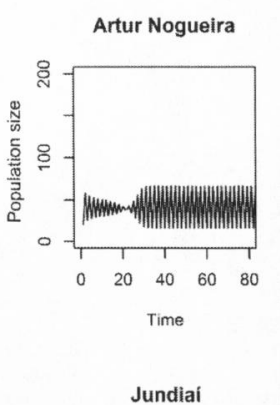

Chrysomya megacephala
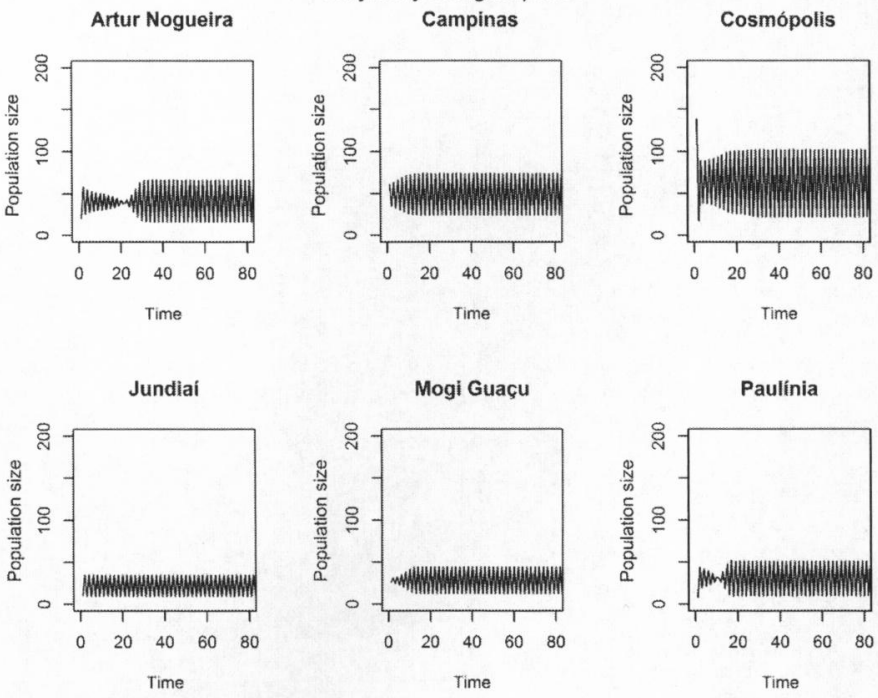

Figure 2. Recurrence obtained from equation (4) showing the population dynamics of Chrysomya megacephala in different municipalities.

\section{Chrysomya albiceps}
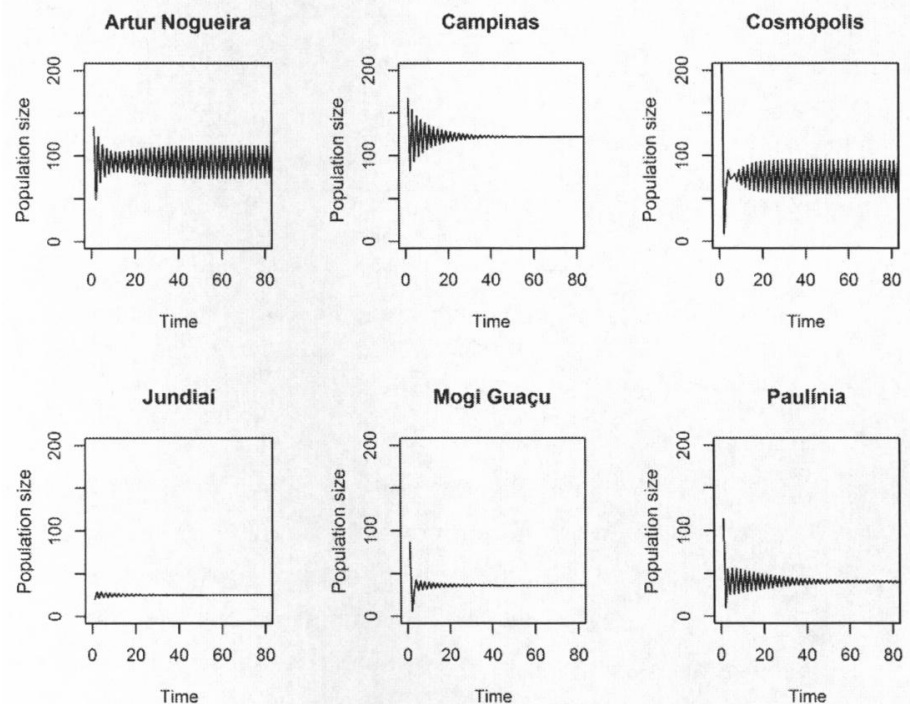

Figure 3. Recurrence obtained from equation (4) showing the population dynamics of Chrysomya albiceps in different municipalities.
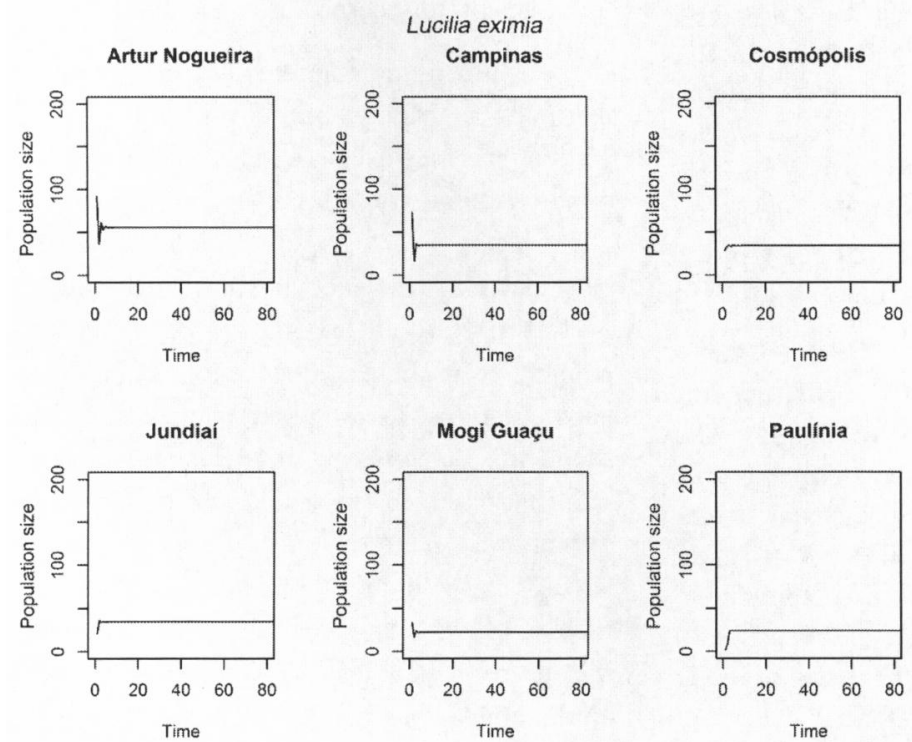

Figure 4. Recurrence obtained from equation (4) showing the population dynamics of Lucilia eximia in different municipalities. 
Table 3. Estimates of the parameters of the model for Chrysomya albiceps in the different municipalities.

\begin{tabular}{|c|c|cc|c|c|c|}
\hline \multirow{2}{*}{ Parameter } & \multicolumn{7}{|c|}{ Estimate } \\
\cline { 2 - 7 } & AN & CAM & COS & JUN & MOG & PAU \\
\hline$N_{0}$ & 134 & 167 & 223 & 20 & 87 & 114 \\
\hline$u^{*}$ & 92.14 & 127.21 & 73.00 & 26.29 & 37.93 & 34.86 \\
\hline$P$ & \multicolumn{7}{|c|}{27.11} \\
\hline$Q$ & \multicolumn{7}{|c|}{0.5650} \\
\hline$(p+q)$ & 0.0258 & 0.0187 & 0.0325 & 0.0904 & 0.0626 & 0.0682 \\
\hline$\alpha$ & \multicolumn{7}{|c|}{1.80} \\
\hline$M_{i}$ & \multicolumn{7}{|c|}{0.10} \\
\hline
\end{tabular}

Table 4. Estimates of the parameters of the model for Chrysomya megacephala in the different municipalities.

\begin{tabular}{|c|c|c|c|c|c|c|}
\hline \multirow{2}{*}{ Parameter } & \multicolumn{6}{|c|}{ Estimate } \\
\cline { 2 - 7 } & AN & CAM & COS & JUN & MOG & PAU \\
\hline$N_{0}$ & 20 & 61 & 138 & 10 & 26 & 8 \\
\hline$u^{*}$ & 37.00 & 49.07 & 62.29 & 23.14 & 29.36 & 28.86 \\
\hline$P$ & \multicolumn{6}{|c|}{23.49} \\
\hline$Q$ & \multicolumn{7}{|c|}{0.9160} \\
\hline$(p+q)$ & 0.0642 & 0.0484 & 0.0381 & 0.1027 & 0.0809 & 0.0823 \\
\hline$a$ & \multicolumn{7}{|c|}{1.80} \\
\hline$M_{i}$ & \multicolumn{7}{|c|}{0.10} \\
\hline
\end{tabular}

Table 5. Estimates of the parameters of the model for Lucilia eximia in the different municipalities.

\begin{tabular}{|c|c|c|c|c|cc|}
\hline \multirow{2}{*}{ Parameter } & \multicolumn{7}{|c|}{ Estimate } \\
\cline { 2 - 7 } & AN & CAM & COS & JUN & MOG & PAU \\
\hline$N_{0}$ & 92 & 73 & 29 & 21 & 34 & 2 \\
\hline$u^{\star}$ & 55.79 & 34.71 & 31.21 & 37.21 & 24.29 & 23.21 \\
\hline$P$ & \multicolumn{7}{|c|}{9.08} \\
\hline$Q$ & \multicolumn{7}{|c|}{1.00} \\
\hline$(P+q)$ & 0.0271 & 0.0436 & 0.0485 & 0.0407 & 0.0623 & 0.0652 \\
\hline$\alpha$ & \multicolumn{7}{|c|}{1.80} \\
\hline$M_{i}$ & \multicolumn{7}{|c|}{0.10} \\
\hline
\end{tabular}

$N_{0}$ : abundance on the first month of collection; $u^{*}$ : sampling average; $P$ : maximum fecundity; $Q$ : survival rate; $(p+q)$ : refer to the text; $\alpha$ : range of flight in $\mathrm{km}$, estimated from Coutinho et al. (2012); $M_{i}$ : proneness to migrate away from site $i$ (illustrative value used in figures 2, 3 and 4, not obtained from data); AN: Artur Nogueira; CAM: Campinas; COS: Cosmópolis; JUN: Jundiaí; MOG: Mogi Guaçu; PAU: Paulínia.

in Campinas and its smallest in Jundiaí. C. megacephala had its largest population in Cosmópolis and its smallest also in Jundiaí. L. eximia had its largest population in Artur Nogueira and its smallest in Paulínia.

The oscillation patterns obtained by simulating the recurrence from equation (4) indicate that $C$. megacephala showed periodic fluctuations in all the municipalities (Fig. 2 ). The stability of $C$. albiceps depended on the municipality, as the pattern obtained for three of them (Campinas, Jundiaí and Mogi Guaçu) is a stable equilibrium (Fig. 3). L. eximia showed only stable equilibrium patterns (Fig. 4). C. megacephala and $L$. eximia showed the same patterns regardless of the municipality, with the main differences being in the peak sizes (C. megacephala) and population size (L. eximia).

The estimates for the parameters used in the model for $C$. albiceps, $C$. megacephala and $L$. eximia in the different municipalities are shown in Tables 3,4 and 5, respectively. The different types of temporal patterns found for C. albiceps suggest that they can be related to their respective parameter values, as previously observed in other studies (Godoy et al. 2001). It is possible that the apparent special demographic condition of $C$. albiceps is connected with its different strategies to obtain food, for example its cannibal behavior in the larval stage, as well as its intraguild predator habit (Faria et al. 2007). In a study on oviposition behavior, L. eximia avoided laying eggs in patches where $C$. albiceps larvae had been present previously (Gião and Godoy 2007), indicating the existence of interaction between the two species. Previous laboratory estimates of survival rates for $C$. albiceps are very low compared to those for other blowfly species (Godoy et al. 2001), probably leading the species to search for compensatory perpetuation strategies.

The bifurcation diagrams obtained for the likelihood of migrating $\left(M_{i}\right.$ parameters) show that, in some cases, high migration rates may lead to extinction (Figs. 5, 6 and 7). On the other hand, intermediate migration rates may act as a stabilizing factor (Figs. 5, 6 and 7). With a few exceptions, the most stable pattern is obtained at intermediate values, as an overall increase in the likelihood of migrating may lead populations in some patches to extinction, which may cause population overflow in other patches and subsequently less stability (Solé and Bascompte 2006). The species that show smaller oscillation spectra are those that are prone to reach stability (Fig. 7). In contrast, the species that oscillate more widely reach higher population levels, increasing their chances of colonizing new areas (Hanski 1999). These latter species may be forensically important, because they will be more abundant in a given area, and then will have higher chances of colonizing cadavers. 

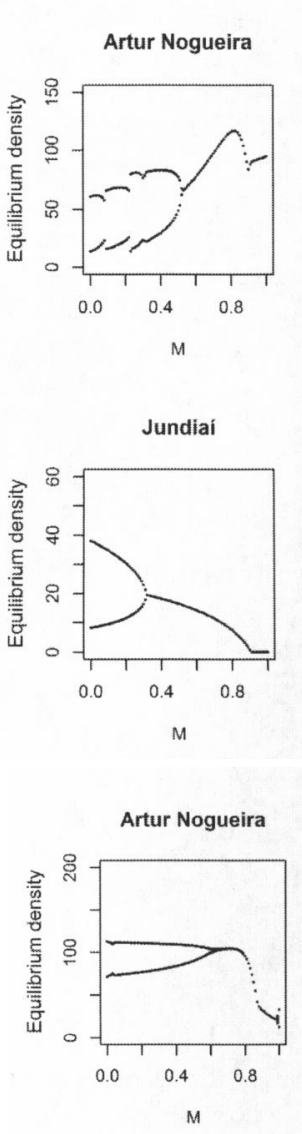

Jundiaí

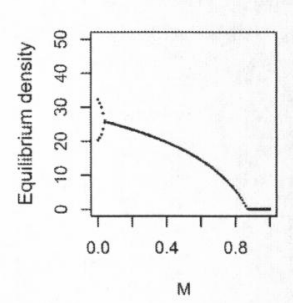

Artur Nogueira

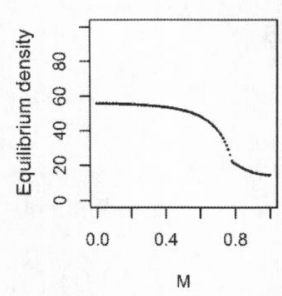

Jundiaí

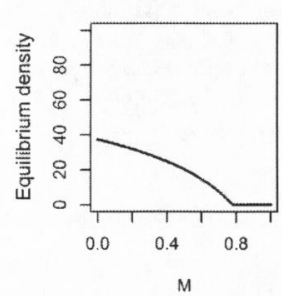

Chrysomya megacephala Campinas
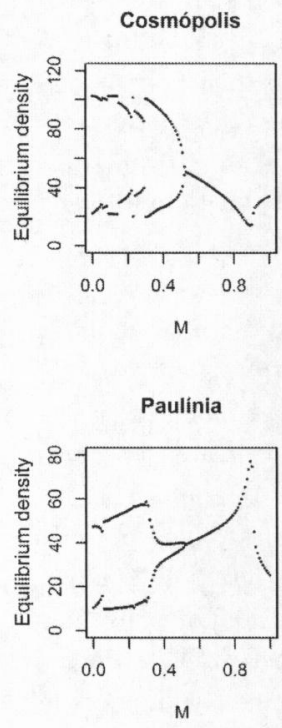

Chrysomya albiceps
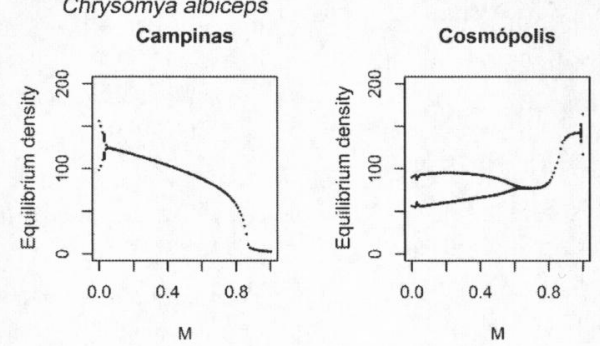

Mogi Guaçu

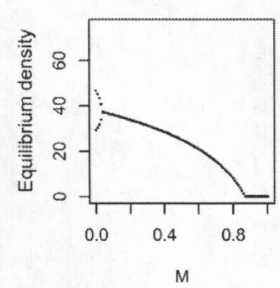

Paulínia

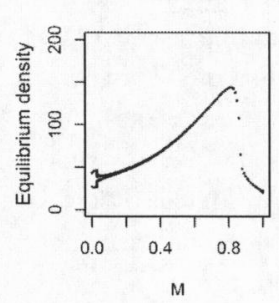

Cosmópolis

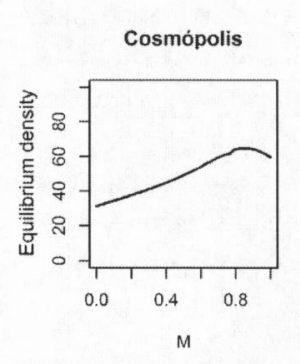

Paulinia
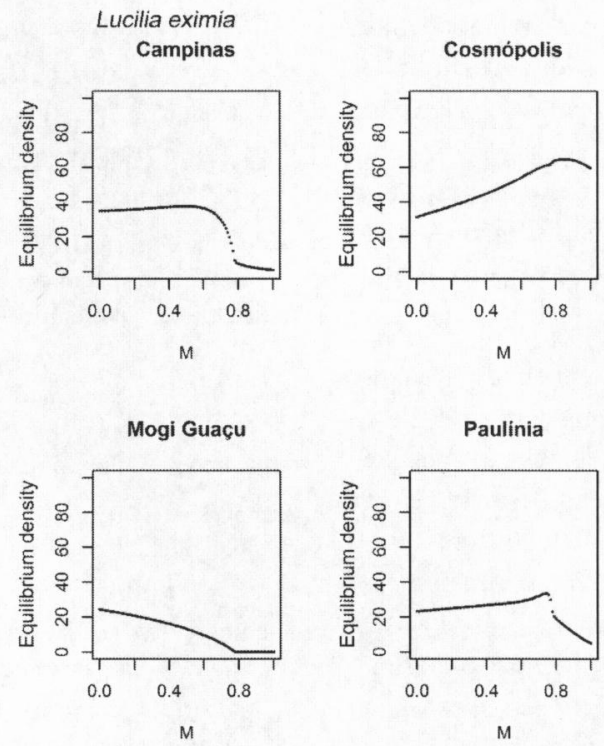

Mogi Guaçu

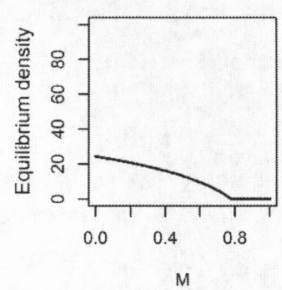

Figure 5. Bifurcation diagram for the likelihood of Chrysomya megacephala migrating away from each municipality (M).

Figure 6. Bifurcation diagram for the likelihood of Chrysomya albiceps migrating away from each municipality (M).

Figure 7. Bifurcation diagram for the likelihood of Lucilia eximia migrating away from each municipality (M). 
Populations located in municipalities distant from each other will certainly show lower migration rates than those located close to each other, and this may lead to distinct faunistic patterns. Knowledge of such patterns is essential for mapping insect species of forensic importance for a given area. The changes in preference for areas shown by blowflies can be easily illustrated by $C$. megacephala. In the first years after its introduction into Brazil, this species was associated with decomposing organic matter and garbage dumps, mainly in urban areas (D'Almeida et al. 1991). However, $C$. megacephala was recently collected in larger numbers in forests (Souza and Von Zuben 2012) and in rural areas (Moretti and Godoy 2013) than in urban areas, also in investigations in São Paulo State. L. eximia, which seems to be especially adapted for colonizing small carcasses (Moretti and Godoy 2013), was formerly found mainly in rural and forest habitats in Brazil (Guimarães and Papavero 1999). However, Moretti and Godoy (2013) collected L. eximia in larger numbers in urban areas than in rural and forest ones, in São Paulo State. C. albiceps has apparently retained its synanthropic behavior since its introduction to Brazil, and continues to be mostly collected in urban areas (Moretti and Godoy 2013).

Migration between adjoining areas has been investigated in insects, particularly with mathematical models emphasizing the dynamics of hosts and parasitoids (Hassell et al. 1991). Among the limitations of models that only consider the recurrences through time is the normal behavior of populations to increase very rapidly, resulting in immediate dramatic declines that usually culminate in extinction. Spatially arranged models usually allow more possibilities, such as the global persistence of locally unstable populations (Hassell et al. 1991). The overall probability of persistence generally increases with the increase in the complexity and size of spatial arrays. Hassell et al. (1991) have shown that some ecological patterns important for population persistence, such as spiral waves, crystal lattices or chaotic variation, can only be obtained when spatial structure is taken into account. Migration may also trigger a rescue effect, when populations decline below critical points, increasing the extinction risk (Serra et al. 2007). These migration effects are more closely related to the idea of conservation biology, but they also should be considered an important factor in pest-management strategies because the level of economic damage can be changed significantly by considering the local migration of pests (Lima et al. 2009).

A limitation of our model is that it considers the six municipalities as a closed system, without considering possible in- and out-migration between the municipalities that we studied and those not included in the system. However, even with this limitation, the study was able to show different impacts of local migration on the quantitative and qualitative population behaviors. Another aspect is that the use of carrion-baited traps, although they are effective for comparing the abundances of necrophagous flies between sites, may bias the collection results (Hwang and Turner 2005).
Acknowledgments. We are indebted to R.A. Kraenkel for his invaluable insights on the development of the mathematical model. TCM, RMC and RAM thank FAPESP (Săo Paulo Research Foundation) for financial support through fellowships. WACG has been partially supported by a grant from CNPq (The National Council for Scientific and Technological Development). The observations reported in this study are part of a Thematic Project named "Forensic Entomology: The utilization of Arthropods for determining time, place, cause, and circumstances of death", supported by FAPESP. Comments from the two referees helped to improve the manuscript.

\section{References}

Burd, M. and J.J. Howard. 2005. Central-place foraging continues beyond the nest entrance: the underground performance of leafcutting ants. Anim. Behav. 70: 737-744.

Choutt, J., C. Turlure, M. Baguette and N. Schtickzelle. 2011. Parasitism cost of living in a high quality habitat in the bog fritillary butterfly. Biodivers. Conserv. 20: 3117-3131.

Costantino, R.F., R.A. Desharnais, J.M. Cushing, B. Dennis, S.M. Henson and A.A. King. 2005. Nonlinear stochastic population dynamics: the flour beetle Tribolium as an effective tool of discovery. Adv. Ecol. Res. 37: 101-141.

Coutinho, R.M., W.A.C. Godoy and R.A. Kraenkel. 2012. Integrodifference model for blowfly invasion. Theor. Ecol. 5: 363371.

D’Almeida, J.M., N.C. Jourdan and S. Cesário. 1991. Dípteros caliptratos sinantrópicos do Aterro Sanitário de Jardim Gramacho, Rio de Janeiro. Rev. Bras. Biol. 2: 307-311.

Deshamais, R.A. 2005. Population Dynamics and Laboratory Ecology, Volume 37, Advances in Ecological Research, Academic Press, New York.

Faria, L.D.B., C. Reigada, L.A. Trinca and W.A.C. Godoy. 2007. Foraging behaviour by an intraguild predator blowfly, Chrysomya albiceps (Diptera: Calliphoridae). J. Ethol. 25: 287294.

Fuller, E., B.D. Elderd and G. Dwyer. 2012. Pathogen persistence in the environment and insect-baculovirus interactions: diseasedensity thresholds, epidemic burnout, and insect outbreaks. Am. Nat. 179 (3): E70-E96.

Gião, J.Z. and W.A.C. Godoy. 2007. Ovipositional behavior in predator and prey blowflies. J. Insect Behav. 20: 77-86.

Godoy, W.A.C. 2007. Dynamics of blowfly populations. Func. Ecosyst. Commun. 1: 129-139.

Godoy, W.A.C., C.J. Von Zuben, S.F. Reis and F.J. Von Zuben. 1997. The spatial dynamics of native and introduced blowflies (Diptera: Calliphoridae). J. Appl. Entomol. 121: 305-309.

Godoy, W.A.C., F.J. Von Zuben, C.J. Von Zuben and S.F. Reis. 2001. Spatio-temporal dynamics and transition from asymptotic equilibrium to bounded oscillations in Chrysomya albiceps (Diptera, Calliphoridae). Mem. Inst. Oswaldo Cruz 96: 627-634.

Granovskiy, B., T. Latty, M. Duncan, D.J.T. Sumpter and M. Beekman. 2012. How dancing honey bees keep track of changes: the role of inspector bees. Behav. Ecol. 23, 588-596.

Guimarães, J.H. and N. Papavero 1999. Myiasis in Man and Animals in the Neotropical Region, Plêiade, São Paulo.

Gurney, W.S.C., S.P. Blythe and R.M. Nisbet. 1980. Nicholson's blowflies revisited. Nature 1117: 17-21. 
Hamann, H. and T. Schmickl. 2012. Modelling the swarm: Analysing biological and engineered swarm systems. Math. Comp. Model. Dyn. 18: 1-12.

Hanski, I. 1999. Metapopulation Ecology. Oxford University Press, Oxford.

Hassell, M.P., H.N. Comins and R.M. May. 1991. Spatial structure and chaos in insect population dynamics. Nature 353: 255-258.

Hwang, C. and B.D. Turner. 2005. Spatial and temporal variability of necrophagous Diptera from urban to rural areas. Med. Vet. Entomol. 19: 379-391.

IBGE. Instituto Brasileiro de Geografia e Estatística. 2012. (www.ibge.gov.br)

Lima, E.A.B.F., C.P. Ferreira and W.A.C. Godoy. 2009. Ecological modeling and pest population management: a possible and necessary connection in a changing world. Neotrop. Entomol. 38: 699-707.

Moilanen A. and I. Hanski. 2001. On the use of connectivity measures in spatial ecology. Oikos 95: 147-151.

Moilanen A. and M. Nieminen. 2002. Simple connectivity measures in spatial ecology. Ecology 83: 1131-1145.

Morellato, P.C. and H.F. Leitão Filho. 1995. Ecologia e preservação de uma floresta tropical urbana: reserva de Santa Genebra. Editora da UNICAMP, Campinas.

Moretti, T.C., E. Giannotti, P.J. Thyssen, D.R. Solis and W.A.C. Godoy. 2011. Bait and habitat preferences, and temporal variability of social wasps (Hymenoptera: Vespidae) attracted to vertebrate carrion. J. Med. Entomol. 48: 1069-1075.

Moretti, T.C. and W.A.C. Godoy. 2013. Spatio-temporal dynamics and preference for type of bait in necrophagous insects, particularly native and introduced blow flies (Diptera: Calliphoridae). J. Med. Entomol. 50: 415-424.

Nicholson, A.J. 1954. An outline of the dynamics of animal populations. Aust. J. Zool. 2: 9-65.

Nicholson, A.J. 1957. The self-adjustment of populations to change. Cold Spring Harb. Symp. Quant. Biol. 22: 153-173.

Okubo, A. and S.A. Levin. 2001. Diffusion and Ecological Problems: Modern Perspectives. Springer, New York.

Petrovskii, S., D. Bearup, D.A. Ahmed and R. Blackshaw. 2012. Estimating insect population density from trap counts. Ecol. Complex. 10: 69-82.

Prout T. and F. McChesney. 1985. Competition among immatures affects their adult fertility: population dynamics. Am. Nat. 126: 521-558.
Reigada, C., S.B.L. Araujo, M.A.M. Aguiar, J.Z. Gião, P.R. Guimarães Jr., L.A. Trinca and W.A.C. Godoy. 2013. Impacts of enemy-mediated effects and the additivity of interactions in an insect trophic system. Popul. Ecol. 55: 11-26.

Rösch, V., T. Tscharntke, C. Scherber and P. Batáry. 2013. Landscape composition, connectivity and fragment size drive effects of grassland fragmentation on insect communities. J. Appl. Ecol. 50: 387-394.

Rubio, A., M.I. Bellocq and D. Vezzani. 2012. Community structure of artificial container-breeding flies (Insecta: Diptera) in relation to the urbanization level. Landscape Urban Plan. 105: 288295.

Serra, H., I.C.R. Silva, P.F.A. Mancera, L.D.B. Faria, C.J. Von Zuben, S.F. Reis and W.A.C. Godoy. 2007. Stochastic dynamics in coupled populations of exotic and native blowflies (Diptera: Calliphoridae). Ecol. Res. 22: 686-695.

Setzer, J. 1966. Atlas climatológico e ecológico do Estado de São Paulo. Comissão Interestadual da Bacia Paraná-Uruguai. Centrais Elétricas do Estado de São Paulo, São Paulo, Brazil.

Silva, I.C.R., P.F.A. Mancera and W.A.C. Godoy. 2003. Population dynamics of Lucilia eximia (Dipt., Calliphoridae). J. Appl. Entomol. 127: 2-6.

Solé, R.V. and J. Bascompte. 2006. Self-organization in Complex Ecosystems. Princeton University Press, Princeton.

Souza, C.R. and C.J. Von Zuben. 2012. Diversity and synanthropy of Calliphoridae (Diptera) in the region of Rio Claro, SP, Brazil Neotrop. Entomol. 41: 243-248.

Yurk, B.P. and J.A. Powell. 2010. Modeling the effects of developmental variation on insect phenology. Bull. Math. Biol. 72: 1334-1360.

Von Zuben, C.J., S.F. Reis, J.B.R. Val, W.A.C. Godoy and O.B. Ribeiro. 1993. Dynamics of a mathematical model of Chrysomya megacephala (Diptera, Calliphoridae). J. Med. Entomol. 30: 443-448.

Received February 20, 2013 Revised May 30, 2013 Accepted June 19, 2013 